\title{
THERMAL DEGRADATION OF POLYSTYRENE IN AIR
}

The degradation of polystyrene has been a subject of many investigations and a large volume of literature exists on the subject. More recently Cascaval et al. (1) have reported that the weight loss of polystyrene containing end groups derived from azobisisobutyronitrile (AIBN) seems to be different from that of anionically polymerized samples. We have been working for some time with polystyrene having different end groups, and in this communication we would like to report some interesting observations related to the decomposition of some of these polymers.

\section{Purification of Monomer}

Styrene was freed from stabilizer by washing with $5 \%$ aqueous caustic soda followed by repeated washing with distilled water to remove excess of alkali. The monomer was dried over fused calcium chloride by keeping it overnight and with occasional shaking. It was filtered and finally distilled in vacuum and the fraction between $52-53^{\circ} \mathrm{C}$ at $28 \mathrm{~mm}$ pressure was collected.

\section{Purification of Initiators}

The benzoyl peroxide and AIBN were purified by recrystallizing three times from G.R. grade methanol and drying in vacuum at room temperature.

All solvents were of analytical reagent grade and were used without further purification.

-Polystyrene samples were prepared by the usual sealing-tube technique. Required amounts of the monomer, transferring agent, and initiator, if any, were introduced in a cleaned ampule and sealed off in vacuum after degassing by repeated freezing and melting. The sealed tubes were suspended in a thermostat maintained at $95 \pm 0.1^{\circ} \mathrm{C}$. The tubes were taken out at definite intervals of time, chilled into an ice-salt mixture, and broken open. The polymer was precipitated by pouring the reaction mixture into an excess of methanol. The polymers thus obtained were dissolved in benzene, reprecipitated with methanol, and dried in vacuum at $50^{\circ} \mathrm{C}$ for $12 \mathrm{hr}$.

The polystyrene samples prepared as above were used for isothermal weight loss studies at $308-360^{\circ} \mathrm{C}$ in air. The thermogravimetric analysis was carried out in a TGA apparatus constructed in our laboratory and similar to that described by McBain and Baker (2) and by Vasudevamurthy et al. (3). The weight loss with respect to time was determined by the measurement of contraction of a helical quartz spring (supplied by Messrs Thermal Syndicate, U.K). with uniform sensitivity of $0.034 \mathrm{~cm} / \mathrm{mg}$. A cathetometer with a lowest count of $0.001 \mathrm{~cm}$ was used for the measurement of contraction of the spring.

To obtain the rate of decomposition of the polymers a furnace maintained

Journal of Polymer Science: Polymer Letters Edition, Vol. 17, 121-124 (1979) 
TABLE I

Total Percent Weight Loss for Polystyrene Samples ${ }^{a}$

\begin{tabular}{|c|c|c|c|}
\hline Sample No. & $\begin{array}{l}\text { Polys tyrene } \\
\text { with trans- } \\
\text { ferring agents } \\
\text { and or initiator. }\end{array}$ & ; wt.loss. & $2 . P$. \\
\hline 1 & AI BN & 94.4 & 366. \\
\hline 2 & $\begin{array}{l}\text { Benzoyl } \\
\text { peroxide }\end{array}$ & 94.4 & 467. \\
\hline 3 & $\begin{array}{l}\text { Carbon tetra- } \\
\text { chloride. }\end{array}$ & -40.0 & 60. \\
\hline 4 & Bromobenzene & 59.3 & 2506. \\
\hline 5 & Benzene & 57.2 & $4: 10$. \\
\hline 6 & - & 77.6 & $5: 45$. \\
\hline 7 & Ithyl acetate & e 73.4 & 1057. \\
\hline 8 & hcetic acid & 79.4 & 1016. \\
\hline 9 & $\begin{array}{l}\text { letinyl ethyl } \\
\text { ketone }\end{array}$ & 74.00 & 1517. \\
\hline 10 & Vie thylamine & 65.2 & - \\
\hline
\end{tabular}

${ }^{a}$ Experimental temperature: $308^{\circ} \mathrm{C}$; total time: $2 \mathrm{hr}$; atmosphere: air. All samples except 1 and 2 were thermally polymerized.

at constant temperature within $\pm 1{ }^{\circ} \mathrm{C}$ was used in the experimental setup. The temperature of the furnace was measured with the help of a chrome-Alumel thermocouple with one of its junctions in the center of the furnace and just below the sample holder. Before determining the rate of decomposition, the furnace was maintained at the required temperature and was kept for $8-12$ hr to attain equilibrium.

For each run a sample of $50.0 \mathrm{mg}$ was placed into a thin-walled cylindrical platinum hollow bucket (made of foil of $0.025 \mathrm{~mm}$ thickness). The bucket was placed in the furnace maintained at the required temperature and equilibrium was found to be attained within less than $1 \mathrm{~min}$. The zero-time reading was taken after $1 \mathrm{~min}$ of insertion of the sample in the furnace and due correction made for any weight loss during this period. All the samples were studied under similar experimental conditions. The percent weight loss in each case was measured with definite intervals of time for $2 \mathrm{hr}$. The residual mass was checked gravimetrically. The percentage weight loss with respect to time is represented in Figure 1 and the total \% weight loss is given in Table I. The weight loss experiment has been carried out at different temperatures 


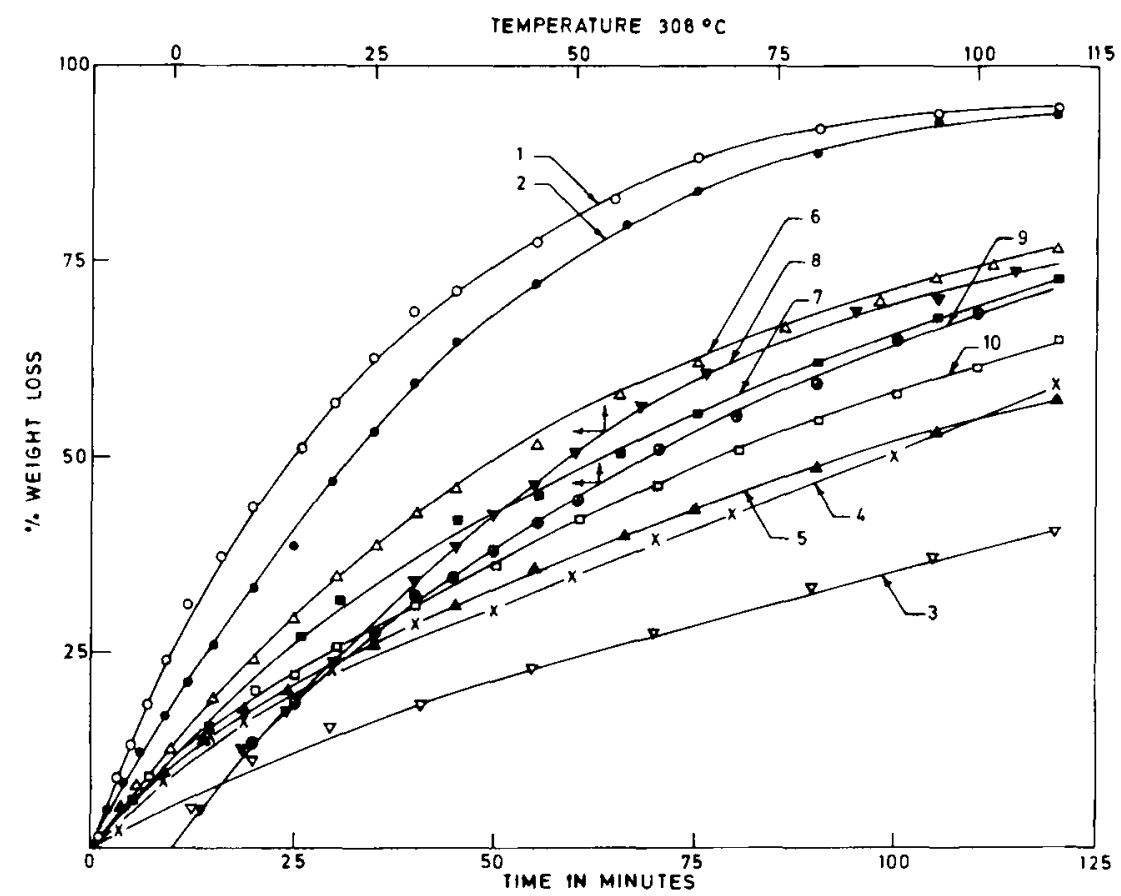

Fig. 1. Percent weight loss of polystyrene samples at different times. Numbers refer to the sample as depicted in Table I.

$\left(308-360^{\circ} \mathrm{C}\right.$ ) and Table I is a representative one for $308^{\circ} \mathrm{C}$. The experiments were repeated at least four times and found to be reproducible within experimental error.

The foregoing results clearly show the significant difference in the extent of decomposition as dependent on the type of end group. Thus polystyrene with halogen end groups prepared in the presence of carbon tetrachloride undergoes only $40 \%$ weight loss as compared to $94.4 \%$ for samples prepared in the presence of AIBN or benzoyl peroxide and $77 \%$ for thermally polymerized sample. The extent of decomposition can be easily seen to be a function of the type of end group indicating that the cause of decomposition is end initiated.

Although we would have expected a higher rate of decomposition for polystyrene sample having DP $=60.0$ for carbon tetrachloride as compared to the thermally polymerized sample of $\mathrm{DP}=5546.0$, in actual experiment the reverse trend is noticed. Such wide variation is larger than would be accounted for by molecular weight effects. Also there is significant difference between 
samples 5 and 6 which is quite surprising. We have carried out IR, UV, and mass spectral analysis, and have some tentative clue to their mode of behavior. At present we refrain from suggesting any mechanistic model for such differences until further work is carried out.

\section{References}

(1) C. N. Cascaval, S. Straus, D. W. Brown, and R. E. Florin, J. Polym. Sci. Symp., 57, 81-88 (1976).

(2) J. W. McBain and A. M. Baker, J. Am. Chem. Soc., 48, 690 (1926).

(3) A. R. Vasudevamurthy, D. S. Bharadwaz, and R. M. Mallya, Chem. Ind., 16, 300 (1956).

Mahendra Singh

U. S. Nandi

Department of Inorganic and

Physical Chemistry

Indian Institute of Science

Bangalore-560 012

India

Received May 9, 1978

Revised October 6, 1978 